\title{
Effects of Topical Nepafenac and Fluorometholone on Macular Thickness After Posterior Capsulotomy Using Neodymium-doped Yttrium-Aluminum-Garnet Laser
}

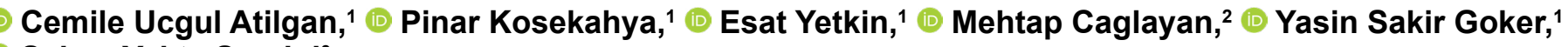 \\ Selam Yekta Sendul ${ }^{3}$
}

1'Department of Ophthalmology, Ulucanlar Goz Training and Research Hospital, Ankara, Turkey

${ }^{2}$ Department of Ophthalmology, Gazi Yasargil Training and Research Hospital, Diyarbakir, Turkey

${ }^{3}$ Department of Ophthalmology, Sisli Hamidiye Etfal Training and Research Hospital, Istanbul, Turkey

\begin{abstract}
Objectives: The aim of this study was to assess the effects of topical $0.1 \%$ nepafenac and $0.1 \%$ fluorometholone on macular thickness (MT) after a neodymium: yttrium-aluminum-garnet (Nd:YAG) laser posterior capsulotomy and to compare the findings with those of untreated patients.

Methods: This prospective study included 75 eyes of 75 patients with posterior capsule opacification. The patients were divided into 3 groups according to the medications administered after a capsulotomy procedure. Group I comprised 25 patients who were prescribed $0.1 \%$ nepafenac for a week, Group 2 consisted of 25 patients who were prescribed $0.1 \%$ fluorometholone for a week, and Group 3 consisted of 25 patients who were not prescribed any medication. A circularshaped capsulotomy was performed in all cases. MT was measured before the capsulotomy and at the first day, first week, and first month after the procedure using spectral domain-optical coherence tomography and the change values were compared within and between groups.

Results: In Group I, the superior and nasal parafoveal MT, temporal, and nasal perifoveal MT values at the first month were statistically significantly greater than those observed in the first week ( $p<0.05$ for all values). In Group 2, the superior and nasal parafoveal MT and inferior perifoveal MT measurements in the first month were greater than those recorded the first week ( $p<0.05$ for all values). In Group 3, there was a gradual increase seen in the first day, first week, and first month in the superior and temporal parafoveal MT value $(p<0.05$ for all). The change value in the parafoveal temporal quadrant was significant between groups, indicating a greater increase in the untreated group compared with the nepafenac and fluorometholone groups $(p=0.04)$.

Conclusion: An increase in MT can occur after an Nd:YAG laser posterior capsulotomy. Both topical $0.1 \%$ nepafenac and $0.1 \%$ fluorometholone can prevent this increase. The 2 drugs were comparable; neither demonstrated apparent superiority to the other.

Keywords: Fluorometholone, macular thickness, Nd:YAG laser posterior capsulotomy, nepafenac, posterior capsule opacification.
\end{abstract}

\section{Introduction}

Posterior capsule opacification (PCO) is the most common late complication of cataract surgery (I). PCO emerges with a significant loss in visual acuity and contrast sensitivity (2).
The incidence of PCO is known to be in the range of $5-50 \%$ of eyes following an uneventful cataract surgery (3). A neodymium: yttrium-aluminum-garnet (Nd:YAG) laser posterior capsulotomy is the currently accepted standard treatment

Address for correspondence: Selam Yekta Sendul, MD. Sisli Hamidiye Etfal Egitim ve Arastirma Hastanesi, Oftalmoloji Klinigi, Istanbul Turkey

Phone: +90 5323672295 E-mail: sysendul@hotmail.com

Submitted Date: April 02, 2019 Accepted Date: May 01, 2020 Available Online Date: July 29, 2020

${ }^{\circ}$ Copyright 2020 by Beyoglu Eye Training and Research Hospital - Available online at www.beyoglueye.com OPEN ACCESS This work is licensed under a Creative Commons Attribution-NonCommercial 4.0 International License. 
for PCO (4-5). While an Nd:YAG laser posterior capsulotomy is a reliable, effective, and noninvasive method, it may lead to some rare complications, some of which can be sight-threatening, such as retinal detachment and cystoid macular edema (CME) (5-8).

It has been established that an Nd:YAG laser capsulotomy can cause acute postoperative inflammation, particularly within the first hours after the procedure, which then gradually decreases in the following days and continues as subclinical inflammation $(9,10)$. Both topical steroids and nonsteroidal anti-inflammatory drugs (NSAIDs) are recommended by most surgeons to prevent inflammation-related complications such as CME, given that the intraocular inflammation following an Nd:YAG laser capsulotomy is thought to be transient and minimal. At present, there is no consensus on a superior or preferred agent. The synergistic effect of the combined use of a topical NSAID and steroid has been seen to prevent CME after cataract surgery (I I). Some studies have noted that topical NSAIDs may be slightly more effective than steroids at reducing CME because it decreases the production of prostaglandins (PGs) by directly blocking the cylooxygenase enzyme, which is thought to be the cause of CME $(9,12)$.

MT changes may also occur after an Nd:YAG laser capsulotomy without progression to $\mathrm{CME}(7,13-15)$. A previous study investigated the effects of topical nepafenac $0.1 \%$ and topical betamethasone $0.1 \%$ on anterior chamber inflammation and central MT (CMT) using laser flare photometry (LFP) and OCT. The authors concluded that topical NSAIDs and steroidal agents had an equal anti-inflammatory effect in terms of treating a CMT change after an Nd:YAG laser capsulotomy (15).

The objective of this study was to analyze the effects of topical $0.1 \%$ nepafenac and $0.1 \%$ fluorometholone on MT after an Nd:YAG laser posterior capsulotomy and to compare the results with those of untreated patients.

\section{Methods}

This prospective, observational study included 75 eyes of 75 patients with PCO who presented at a tertiary care hospital with the complaint of decreased visual acuity and who had undergone uneventful phacoemulsification at least 6 months earlier. All of the patients were asked to sign a standard informed consent form and approval for this study was obtained from the Ethics Advisory Committee of the Ankara Numune Training and Research Hospital. The research was conducted in accord with the principles of the Helsinki Declaration.

Patients were excluded from the study based on the following criteria: a history of cataract surgery of $<6$ months and/or an intra-ocular surgery other than cataract surgery, a history of ocular trauma, patients with any systemic (e.g., diabetes mellitus) and/or ocular disorder (e. g., age-related macular degeneration), inflammation (e.g., uveitis, vasculitis), age $<40$ or $>80$ years, refraction error greater than $-2 /+2$ diopters.

The patients were divided into 3 groups each consisting of 25 eyes of 25 patients who were similar in terms of age and gender. PCO was diagnosed by a single individual using the slit-lamp biomicroscopy with retroillumination technique. Once the diagnosis was made, the Nd:YAG laser posterior capsulotomy was performed in the laser room.

Thirty minutes before the laser capsulotomy, I\% tropicamide (Tropamide; Bilim Ilac, Istanbul, Turkey) and 2.5\% phenylephrine hydrochloride (Mydfrin; Alcon, Fort Worth, TX, USA) solution were administered to all of the eyes for pupillary dilation. Subsequently, $0.5 \%$ proparacaine hydrochloride (Alcaine; Alcon, Fort Worth, TX, USA) was administered to all of the eyes 5 minutes before the procedure to provide anesthesia. A standard contact lens coated with polyacrylic acid gel was placed on the cornea. The Nd:YAG laser posterior capsulotomy was performed by a single operator using the VISULAS R YAG III device (Carl Zeiss, Jena, Germany). The laser beam was focused on the posterior capsule and a posterior capsulotomy was performed forming a clear circular area 3-4 mm diameter. The energy level of the laser was adjusted $1.0-3.0 \mathrm{~mJ}$, depending on the capsular thickness encountered. Each capsulotomy was completed in a single session. The number of laser shots, shot energy level, and total energy level were recorded.

After the Nd:YAG laser posterior capsulotomy, 25 patients received topical $0.1 \%$ nepafenac (Nevanac; Alcon, Fort Worth, TX, USA) 4 times daily for I week (Group I), 25 patients received topical $0.1 \%$ fluorometholone (Flarex; Alcon, Fort Worth, TX, USA) 4 times daily for I week (Group 2), and 25 patients did not receive any medication (Group 3). The nepafenac and fluoromethalone cases revealed no significant differentiation in the outer appearance. The study physician used a random system to allocate a drug to 2 of every 3 patients, with the third not receiving medication.

All of the patients underwent a detailed ophthalmologic examination that included a best corrected visual acuity (BCVA) measurement with a Snellen chart, a Goldmann applanation tonometer evaluation, slit-lamp biomicroscopic examination, fundus evaluation, and MT analysis with SDOCT device (Spectralis OCT; Heidelberg Engineering, Heidelberg, Germany).

The SD-OCT measurements were performed by I individual using the MM6 mapping program $(6 \mathrm{~mm} 2$ map of the macula), which has been proven to be reliable (signal strength index $>50$ ) following the full pupillary dilation. MT was measured in the central macula at I mm diameter, in the 
parafoveal field at $3 \mathrm{~mm}$ diameter, and in the perifoveal field at $6 \mathrm{~mm}$ diameter (ETDRS early treatment of diabetic retinopathy study map), and divided into 4 quadrants: the superior, inferior, temporal, and nasal locations. In the parafoveal and perifoveal fields, the thickness values were calculated as the average of the quadrant.

The patients were examined at baseline and the first day, first week, and first month after the Nd:YAG laser capsulotomy. All of the examinations and measurements were repeated at each visit and the parameters and complications, if any, were noted.

\section{Statistical Analysis}

The statistical analysis was performed using PASW Statistics for Windows, Version 18.0 software (SPSS Inc., Chicago, IL, USA). The normality of the data was evaluated with the Kolmogorov-Smirnov test. Descriptive statistics were generated as mean $\pm S D$. The Friedman test was used to evaluate the time-related change in MT in each group. The Wilcoxon test was used to compare the MT values recorded in each examination. The Kruskal-Wallis test was used for the comparison of the average change in MT values between the groups. A P value of $<0.05$ was considered statistically significant.

\section{Results}

The mean age of the study patients was $63.78 \pm 18.0$ years in Group I, 69.76 I I .2 years in Group 2, and 65.75 \pm I 4.0 years in Group $3(p=0.64)$. The groups were similar in terms of gender distribution $(p=0.20)$. No significant difference was found between the 3 groups in the mean values recorded for laser shot count, shot energy level, total energy level, or the interval between the cataract surgery and $\mathrm{Nd}$ :YAG laser posterior capsulotomy $(p=0.19, p=0.05, p=0.46$, and $p=0.39$, respectively) (Table I).
The MT values of patients in the nepafenac group are summarized in Table 2 and Table 3 . Foveal, inferior, and temporal parafoveal, superior, and inferior perifoveal MT values did not significantly change during the first month of follow-up ( $p=0.06, p=0.43, p=0.18, p=0.37$, and $p=0.85$, respectively). The superior and nasal parafoveal MT and the temporal and nasal perifoveal MT values, however, were seen to have increased significantly at the first month follow-up control $(p=0.01, p=0.01, p<0.00 I$, and $p=0.01$ respectively). When the mean values of each examination were compared, no significant difference was found between the baseline and the first day, baseline and first week, first day and first week, and baseline and first month measurements $(p>0.05$ for all). The MT values at the first month were significantly greater than the MT values of the first day and first week $(p<0.05$ for all).

The MT values of the patients in the fluorometholone group are summarized in Table 2 and Table 3 . The foveal, inferior and temporal parafoveal, superior, temporal, and nasal perifoveal MT values did not change significantly during the first month of follow-up $(p=0.07, p=0.06, p=0.15, p=0.14$, $p=0.14$, and $p=0.28$, respectively). The superior and nasal parafoveal and the inferior perifoveal MT values were observed to have increased significantly at the I-month follow-up visit $(p=0.007, p=0.01$, and $p=0.00$ I respectively). When the mean values of each examination were compared, there was no significant difference observed between the baseline and the first day, baseline and first week, first day and first week, baseline and first month measurements ( $p>0.05$ for all values). The MT values at the first month were significantly higher than the MT values observed at day I and week I ( $p<0.05$ for all).

The MT values of the untreated group are summarized

Table I. Clinical and demographic characteristics of the study groups

\begin{tabular}{|c|c|c|c|c|}
\hline & $\begin{array}{c}\text { Group I } \\
\text { (0.1\% nepafenac) } \\
\text { Mean } \pm \text { SD } \\
(n=25)\end{array}$ & $\begin{array}{c}\text { Group } 2 \\
\text { (0.1\% fluorometholone) } \\
\text { Mean } \pm S D \\
(n=25)\end{array}$ & $\begin{array}{c}\text { Group } 3 \\
\text { (control) } \\
\text { Mean } \pm S D \\
(n=25)\end{array}$ & $\mathbf{p}$ \\
\hline Age (years) & $63.78 \pm 18.0$ & $69.76 \pm 11.2$ & $65.75 \pm 14.0$ & $0.648 *$ \\
\hline Total energy level (mj) & $41.5 \pm 23.6$ & $51.7 \pm 22.5$ & $57.7 \pm 29.7$ & $0.466 *$ \\
\hline Shot number (count) & $33.06 \pm 13.14$ & $40.62 \pm 16.72$ & $40.06 \pm 25.16$ & $0.193 *$ \\
\hline Shot energy (mj) & $1.20 \pm 0.50$ & $1.27 \pm 0.37$ & $1.62 \pm 0.62$ & $0.053 *$ \\
\hline
\end{tabular}

*:Kruskal-Wallis test; $\uparrow:$ Fisher's exact test; F: Female; M: Male; mJ: Millijoule. 
Table 2. Foveal and parafoveal macular thickness values of the groups at I-month follow-up after Nd:YAG laser capsulotomy

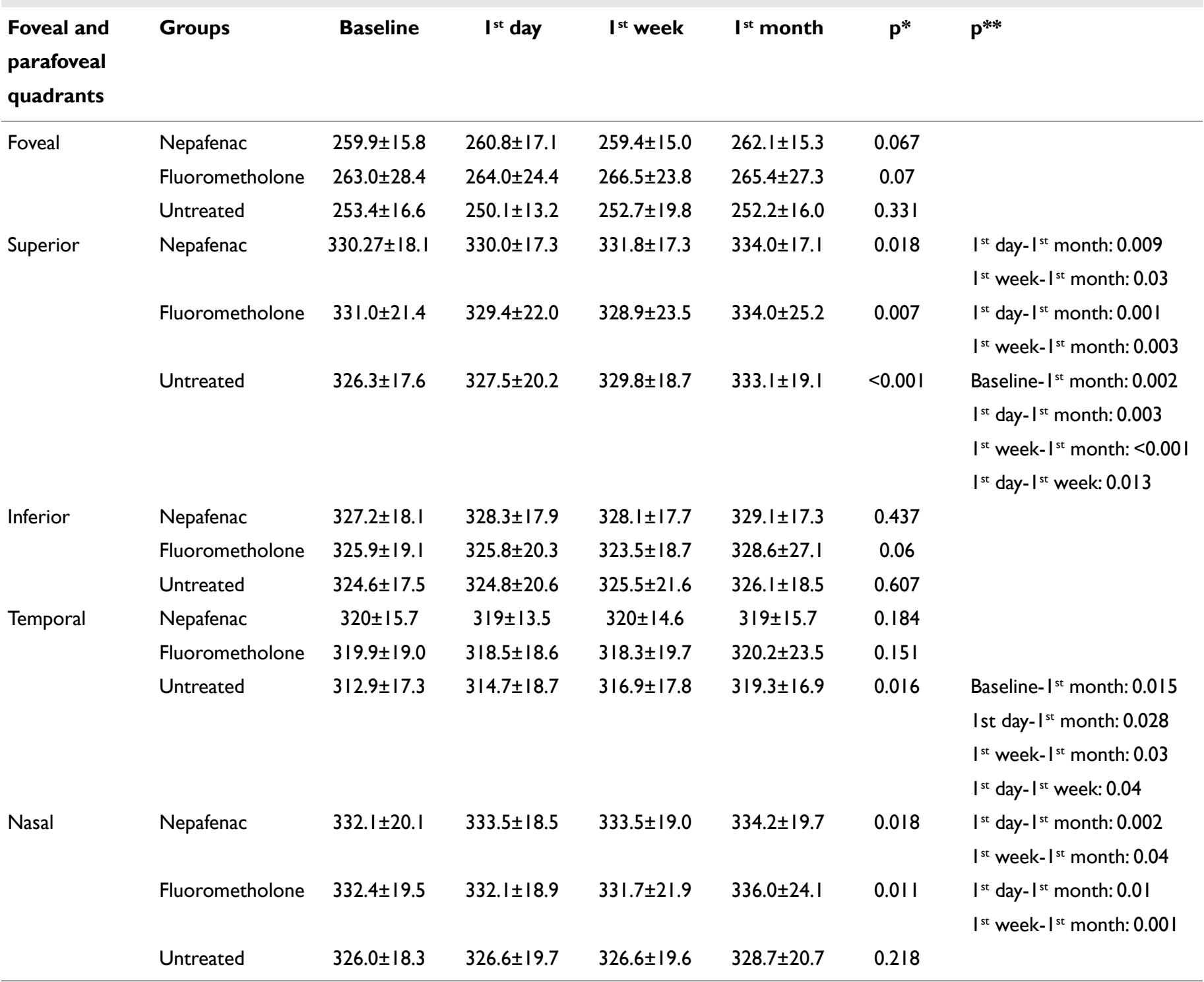

$\mathrm{P}$ (Between groups comparison): Friedman test; $\mathrm{P}$ **(Within group comparison):Wilcoxon test; Nd:YAG: Neodymium-doped yttrium aluminum garnet.

in Table 2 and Table 3. The foveal, inferior and nasal parafoveal, and temporal and nasal perifoveal MT values did not demonstrate a significant change at the first month follow-up $(p=0.33, p=0.60, p=0.21, p=0.89$, and $p=0.18$, respectively). The superior and temporal parafoveal and superior and inferior perifoveal MT values had increased significantly at I month ( $p<0.00 \mathrm{I}, p=0.0 \mathrm{I}, \mathrm{p}=0.03$, and $p=0.002$, respectively). No significant difference was seen between the baseline and either the first day or first week when the mean values of each examination were compared ( $p>0.05$ for all). The MT values had significantly increased at the first month compared with the baseline, first day, and first week measurements ( $p<0.05$ for all).

The mean change values were compared between groups
$($ Table 4,5$)$ and the values observed in the parafoveal temporal quadrant between the baseline and both the first week and first month were significantly different between groups, indicating a greater increase in the untreated group compared with nepafenac and fluorometholone groups $(p=0.04)$ (Table 4). There was no case of serious anterior chamber reaction, increased intraocular pressure and CME attributable to the Nd:YAG laser capsulotomy and/or any adverse effects of either drug.

\section{Discussion}

PCO can be a late complication of cataract surgery (I). Surgical damage, the type of intraocular lens (IOL) used, young age, and some cytokines may stimulate residual lens epithe- 
Table 3. Perifoveal macular thickness values of the groups at I-month follow-up after $\mathrm{Nd:YAG} \mathrm{laser} \mathrm{capsulotomy}$

\begin{tabular}{|c|c|c|c|c|c|c|c|}
\hline $\begin{array}{l}\text { Perifoveal } \\
\text { quadrants }\end{array}$ & Groups & Baseline & I $^{\text {st }}$ day & I $^{\text {st }}$ week & 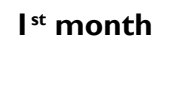 & $\mathbf{p}^{*}$ & $\mathbf{p}^{* *}$ \\
\hline \multirow[t]{4}{*}{ Superior } & Nepafenac & $299.6 \pm 25.3$ & $295.6 \pm 17.2$ & $293.0 \pm 17.5$ & $294.3 \pm 19.8$ & 0.371 & \\
\hline & Fluorometholone & $298.6 \pm 33.1$ & $292.7 \pm 29.1$ & $293.0 \pm 29.4$ & $298.1 \pm 27.3$ & 0.148 & \\
\hline & Untreated & $296.3 \pm 16.3$ & $296.4 \pm 18.4$ & $30 I . I \pm 20.2$ & $302.0 \pm 18.0$ & 0.039 & Baseline- Ist month: 0.024 \\
\hline & & & & & & & $I^{\text {st }}$ day- $I^{\text {st }}$ week: 0.002 \\
\hline \multirow[t]{4}{*}{ Inferior } & Nepafenac & $290.1 \pm 28.6$ & $287.4 \pm 19.2$ & $287.0 \pm 20.0$ & $289.4 \pm 17.0$ & 0.854 & \\
\hline & Fluorometholone & $286.8 \pm 24.0$ & $283.7 \pm 25.8$ & $284.3 \pm 27.2$ & $291.8 \pm 28.3$ & 0.001 & $1^{\text {st }}$ day-I $\left.\right|^{\text {st }}$ month: 0.006 \\
\hline & & & & & & & I st $^{\text {st }}$ week-I Ist month: 0.004 \\
\hline & & & & & & & Ist $^{\text {st }}$ day- $\left.\right|^{\text {st }}$ week: 0.005 \\
\hline \multirow[t]{4}{*}{ Temporal } & Nepafenac & $284.0 \pm 30.8$ & $278.1 \pm 15.4$ & $274.7 \pm 14.6$ & $279.8 \pm 14.5$ & $<0.001$ & $\left.\right|^{\text {st }}$ day- $\left.\right|^{\text {st }}$ month: 0.005 \\
\hline & & & & & & & $\left.\right|^{\text {st }}$ week- $\left.\right|^{\text {st }}$ month: $<0.00 \mid$ \\
\hline & Fluorometholone & $274.1 \pm 19.7$ & $275.8 \pm 20.0$ & $274.3 \pm 20.6$ & $278.5 \pm 21.7$ & 0.149 & \\
\hline & Untreated & $278.6 \pm 22.2$ & $278.3 \pm 20.6$ & $279.0 \pm 20.9$ & $278.3 \pm 20.3$ & 0.893 & \\
\hline \multirow[t]{3}{*}{ Nasal } & Nepafenac & $301.3 \pm 19.0$ & $302.3 \pm 18.5$ & $303.9 \pm 18.3$ & $305.3 \pm 18.2$ & 0.01 & $\left.\right|^{\text {st }}$ day-I Ist $^{\text {month: } 0.00 I}$ \\
\hline & & & & & & & $\left.\right|^{\text {st }}$ week- ${ }^{\text {st }}$ month:0.004 \\
\hline & Fluorometholone & $306.2 \pm 22.2$ & $306.0 \pm 22.3$ & $305.2 \pm 22.1$ & $307.1 \pm 24.2$ & 0.289 & \\
\hline
\end{tabular}

P* (Between groups comparison): Friedman test; $\mathrm{P}^{* *(W i t h i n ~ g r o u p ~ c o m p a r i s o n): W i l c o x o n ~ t e s t ; ~ N d: Y A G: ~ N e o d y m i u m-d o p e d ~ y t t r i u m ~}$ aluminum garnet.

lium cells in the capsule after cataract surgery, which may result in PCO $(1,6,7,16)$.

The Nd:YAG laser posterior capsulotomy procedure is very useful in the treatment of PCO. Nonetheless, while it is considered to be noninvasive and more reliable than surgical discission, there may be some complications, such as retinal detachment, IOL damage, glaucoma, uveitis, and CME (5). The CME incidence following Nd:YAG laser posterior capsulotomy varies between $0.7-4.9 \%(5,17)$. It is thought to be the result of increased perifoveal capillary permeability in the presence of inflammatory mediators such as PGs following a laser capsulotomy procedure.

There is no consensus on whether topical NSAIDs or topical steroids are effective in the treatment of postoperative inflammation. Our aim in this study was to investigate the effects of topical $0.1 \%$ nepafenac and $0.1 \%$ fluorometholone on MT values following an $\mathrm{Nd}$ :YAG laser capsulotomy and to compare the findings with those of untreated patients.
Both topical NSAIDs and topical steroids are commonly used in ophthalmic practice. They generate effects by inhibiting the inflammatory response via different pathways. Steroids inhibit the transcription of pro-inflammatory genes and suppress the production of inflammatory cytokines and also increase the expression of anti-inflammatory genes. NSAIDs directly inhibit the activity of cyclooxygenase enzymes directly and decrease the production of PGs, which mediate the inflammatory process.

Generally, topical NSAIDs are preferred after cataract surgery, and especially in combination with topical steroids. Miyake et al. (18) compared the effectiveness of topical $0.1 \%$ nepafenac and topical $0.1 \%$ fluorometholone after cataract surgery and concluded that nepafenac was more effective at preventing deterioration in the blood-aqueous barrier and CME in patients who were medicated for 5 weeks.

A recent European multicenter trial examining the prevention of CME after cataract surgery in nondiabetics, the European Society of Cataract and Refractive Surgeons PRE- 


\begin{tabular}{|c|c|c|c|c|c|c|c|}
\hline $\begin{array}{l}\text { Foveal and } \\
\text { parafoveal } \\
\text { quadrants }\end{array}$ & Groups & Baseline- Ist $^{\text {stay }}$ & $\mathbf{p}^{*}$ & Baseline- I $^{\text {st }}$ week & $\mathbf{p}^{*}$ & Baseline- $I^{\text {st }}$ month & $\mathbf{p}^{*}$ \\
\hline \multirow[t]{3}{*}{ Foveal } & Nepafenac & $0.94 \pm 4.62$ & 0.53 & $-0.50 \pm 8.64$ & 0.70 & $2.22 \pm 8.17$ & 0.69 \\
\hline & Fluorometholone & $1.04 \pm 12.94$ & & $3.52 \pm 13.76$ & & $3.42 \pm 12.27$ & \\
\hline & Untreated & $-3.31 \pm 9.22$ & & $-0.68 \pm 20.21$ & & $-1.18 \pm 12.80$ & \\
\hline \multirow[t]{3}{*}{ Superior } & Nepafenac & $-2.00 \pm 7.38$ & 0.86 & $-0.88 \pm 7.45$ & 0.12 & $1.22 \pm 8.55$ & 0.13 \\
\hline & Fluorometholone & $-1.52 \pm 7.0 \mid$ & & $-2.09 \pm 7.11$ & & $3.04 \pm 10.26$ & \\
\hline & Untreated & $-0.8 I \pm 4.96$ & & $2.50 \pm 6.01$ & & $5.75 \pm 5.77$ & \\
\hline \multirow[t]{3}{*}{ Inferior } & Nepafenac & $-0.88 \pm 5.31$ & 0.82 & $0.88 \pm 6.81$ & 0.07 & $1.94 \pm 7.86$ & 0.93 \\
\hline & Fluorometholone & $-0.04 \pm 3.47$ & & $-2.38 \pm 7.35$ & & $2.76 \pm 10.65$ & \\
\hline & Untreated & $0.12 \pm 6.03$ & & $0.81 \pm 10.57$ & & $1.43 \pm 6.30$ & \\
\hline \multirow[t]{3}{*}{ Temporal } & Nepafenac & $-|.44 \pm 7.4|$ & 0.43 & $-0.22 \pm 6.62$ & 0.04 & $-1.05 \pm 11.96$ & 0.04 \\
\hline & Fluorometholone & $-1.38 \pm 5.22$ & & $-1.52 \pm 4.5 \mid$ & & $0.38 \pm 9.01$ & \\
\hline & Untreated & $1.8 \mathrm{I} \pm 6.37$ & & $4.00 \pm 7.69$ & & $6.37 \pm 9.98$ & \\
\hline \multirow[t]{3}{*}{ Nasal } & Nepafenac & $-5.94 \pm 28.05$ & 0.72 & $0.33 \pm 6.89$ & 0.27 & $1.00 \pm 10.32$ & 0.78 \\
\hline & Fluorometholone & $-0.33 \pm 7.22$ & & $-0.76 \pm 9.19$ & & $3.57 \pm 10.33$ & \\
\hline & Untreated & $0.62 \pm 5.47$ & & $0.62 \pm 7.41$ & & $2.75 \pm 7.09$ & \\
\hline
\end{tabular}

*Kruskal-Wallis test; Nd:YAG: Neodymium-doped yttrium aluminum garnet.

vention of Macular EDema after cataract surgery (ESCRS PREMED) study, reported that the mean CMT was significantly lower in patients who received combination therapy (bromfenac $0.09 \%$ and dexamethasone $0.1 \%$ ). The MT value was also lower in patients receiving only bromfenac compared with patients receiving only dexamethasone therapy, though not to a level that was statistically significant (I I).

The use of topical steroids or NSAIDs in the treatment of inflammation after Nd:YAG laser capsulotomy varies from patient to patient depending on the severity of ocular inflammation. While some patients require no therapy following laser treatment, some patients with iritis require topical steroids or topical NSAIDs 4 times daily for I week or more post Nd:YAG laser posterior capsulotomy. We did not have any patients with any condition that would require more than I week of treatment. However, in practice, either topical steroids or NSAIDs are usually used as prophylactic mediators to prevent CME $(9,15)$.

Increased retinal thickness without CME can occur after an Nd:YAG laser capsulotomy. There are many studies in the literature that have investigated the effect of topical steroid use on MT after an Nd:YAG laser capsulotomy. Altiparmak et al. (19) administered I\% prednisolone and brimonidine tartrate for a week after an Nd:YAG laser capsulotomy and did not find a significant difference in the MT values in a I-year follow-up study. Giocanti-Auregan et al. (20) used topical rimexolone and acetazolamide for a week after an Nd:YAG laser capsulotomy and did not find any significant increase in MT values in a 3-month follow-up. Wroblewska-Czajka et al. (2I) did not determine a significant difference in the CMT measurements of post-YAG laser capsulotomy patients at the first day, first week, third month, or sixth month. In a study conducted by Ari et al. (14), the patients were divided into 2 groups based on the quantity of laser energy used ( $>$ or $<80 \mathrm{~mJ}$ ) and all of the patients were administered $0.5 \%$ apraclonidine and $1 \%$ prednisolone for a week after the procedure. A significant increase in the MT measurement was observed in both groups, with a greater increase reported in the $>80 \mathrm{~mJ}$ group. Karahan et al. (13) administered topical I\% prednisolone and $0.5 \%$ apraclonidine for 5 days after an Nd:YAG laser capsulotomy and divided the study participants into 2 groups based on the size of the capsulotomy. A significant increase was reported in the MT value in the first week in both groups, which decreased to preoperative levels at the post-laser fourth week, regardless of the capsulotomy size.

There are only a few studies in the literature comparing the effects on MT of topical NSAIDs and steroids used after an Nd:YAG laser capsulotomy. Yilmaz et al. (24) examined the effects of topical $0.1 \%$ fluorometholone alone 
Table 5. The intergroup comparison of perifoveal macular thickness at first day, first week, and first month after Nd:YAG laser capsulotomy

\begin{tabular}{|c|c|c|c|c|c|c|c|}
\hline $\begin{array}{l}\text { Perifoveal } \\
\text { quadrants }\end{array}$ & Groups & Baseline- I day & $\mathbf{p}^{*}$ & Baseline- I ${ }^{\text {st }}$ week & $\mathbf{p}^{*}$ & Baseline- I $^{\text {st }}$ month & $\mathbf{p}^{*}$ \\
\hline \multirow[t]{3}{*}{ Superior } & Nepafenac & $-3.83 \pm 13.20$ & 0.87 & $-6.56 \pm 14.60$ & 0.11 & $-3.77 \pm 15.13$ & 0.16 \\
\hline & Fluorometholone & $-5.85 \pm 24.81$ & & $-5.60 \pm 24.50$ & & $-0.50 \pm 26.89$ & \\
\hline & Untreated & $-0.62 \pm 7.84$ & & $4.80 \pm 12.39$ & & $3.25 \pm 5.36$ & \\
\hline \multirow[t]{2}{*}{ Inferior } & Nepafenac & $-2.66 \pm 16.26$ & 0.55 & $-4.70 \pm 17.93$ & 0.13 & $-0.66 \pm 20.53$ & 0.24 \\
\hline & Untreated & $-1.87 \pm 6.00$ & & $2.37 \pm 7.58$ & & $7.37 \pm 9.54$ & \\
\hline \multirow[t]{3}{*}{ Temporal } & Nepafenac & $-5.88 \pm 23.90$ & 0.40 & $-9.22 \pm 24.40$ & 0.06 & $-4.11 \pm 23.13$ & 0.29 \\
\hline & Fluorometholone & $I .7 I \pm 6.65$ & & $0.23 \pm 6.4 \mathrm{I}$ & & $4.38 \pm 7.52$ & \\
\hline & Untreated & $0.12 \pm 4.52$ & & $0.31 \pm 5.86$ & & $-0.31 \pm 6.98$ & \\
\hline
\end{tabular}

*Kruskal-Wallis test.

and combined topical $0.5 \%$ ketorolac and $0.1 \%$ fluorometholone treatment in diabetic and non-diabetic patients after an Nd:YAG laser capsulotomy. They concluded that the MT values significantly increased after the capsulotomy in both the diabetic and non-diabetic patients who were administered $0.1 \%$ fluorometholone alone, but did not increase in either diabetic or non-diabetic patients using combined treatment. The authors have suggested that the combination of topical ketorolac tromethamine and fluorometholone after an Nd:YAG laser capsulotomy might be more effective in preventing an increase in MT. However, this study compared the effects of combined and single steroid treatments without the benefit of comparison with NSAIDs and steroids. Jinagal et al. (I5) evaluated the anti-inflammatory effects of topical nepafenac $0.1 \%$ alone and betamethasone 0.1 $\%$ alone following an Nd:YAG laser capsulotomy using laser flare photometry (LFP). They detected a significant increase in the LFP values 2 hours post laser capsulotomy that declined gradually and returned to pre-laser values in 2 weeks. Furthermore, they found that the CMT value had increased significantly at 2 weeks and then decreased at the fourth post-laser week without a significant superiority seen between topical NSAIDs and steroids in terms of decreasing ocular inflammation. Their follow-up period was I month, as in our study. The ocular inflammation after a YAG laser capsulotomy treatment is intense in the first hours and gradually decreases over time (I5).

In our study, there was no significant increase in MT observed at the first week after an Nd:YAG laser capsulotomy during treatment with nepafenac or fluorometholone. How- ever, a significant increase in MT was determined at the first month when compared with the first day and first week and approximated baseline values. No significant difference in MT was found between nepafenac and fluorometholone groups in intergroup comparisons after the procedure. It could be concluded that, in both groups, the treatment eliminated the increased thickness that occurred in the first week and the MT value started to increase after the treatment had been terminated.

In the untreated group, there was a significant increase in MT in the first week and the values of the first month were significantly higher than the baseline, indicating a subclinical increase in the macula after the Nd:YAG laser capsulotomy. In the jinagal et al. study, the MT values of the untreated group increased in the first two weeks and returned to their normal values in the first month without the need for treatment (I5). However, in this study, the LFP and CMT values of the untreated patients were higher than those of the treated patients at the fourth week, although the difference was not statistically significant. In our study, the elevation of MT values in the fourth week compared to baseline was too little to require treatment clinically, even though statistically significant.

These findings suggest that medication is recommended after Nd:YAG laser capsulotomy, and either topical NSAIDs or topical steroids may be used. Topical NSAIDs could be preferable used alone, particularly in cases where steroid use might be harmful such as steroid responders, recurrent herpetic keratitis, and where there is a greater risk for CME, such as in diabetic patients (25). 
The limitations of the study are the small number of patients included in each group and the short follow-up period. However, our aim was to investigate the short-term effects of the treatment on MT. Further studies with larger samples and a longer follow-up period with different topical NSAIDs could clarify the outcomes further.

\section{Conclusion}

An Nd:YAG laser posterior capsulotomy is an effective, quick, and noninvasive procedure, but it is likely to cause a subclinical increase in MT. Topical medication is highly recommended after an Nd:YAG laser capsulotomy. Although there is no significant difference between the effectiveness of topical NSAIDs and topical steroids after an Nd:YAG laser capsulotomy, topical nepafenac may be preferred in at-risk patients due to fewer side effects.

\section{Disclosures}

Ethics Committee Approval: Ankara Numune Training and Research Hospital, Date: 08/05/2018, Number: E-I8-I797.

Peer-review: Externally peer-reviewed.

Conflict of Interest: None declared.

Authorship Contributions: Involved in design and conduct of the study (CUA, PK, EY); preparation and review of the study (CÜA, PK, EY, YSG, SYS); data collection (CÜA, EY, MC, SYS); and statistical analysis (MC, PK, YSG).

\section{References}

I. Frezotti R, Caporossi A. Pathogenesis of posterior capsule opacification. Part I. Epidemiological and clinical statistical data. J Cataract Refract Surg 1990; 16:347-52. [CrossRef]

2. Buehl W, Sacu S, Findl O. Association between intensity of posterior capsule opacification and contrast sensitivity. Am J Ophthalmol 2005; I 40:927-30. [CrossRef]

3. Raj SM, Vasavada AR, Johar SRK, Vasavada VA, Vasavada VA. Post-operative capsular opacification: a review. Int J Biomed Sci Master Publ Group 2007;3:237-50.

4. Hayashi K, Hayashi H, Nakado F, Hayashi F. Correlation between posterior capsule opacification and visual function before and after Nd:YAG laser posterior capsulotomy. Am J Ophthalmol 2003;136:720-6. [CrossRef]

5. Aslam TM, Devlin H, Dhillon B. Use of Nd:Yag Laser Capsulotomy. Survey Ophthalmol 2003:48:594-6I2. [CrossRef]

6. Billotte C, Berdeaux G. Adverse clinical consequences of neodymium:YAG laser treatment of posterior capsule opacification. J Cataract Refract Surg 2004;30:2064-7I. [CrossRef]

7. Karahan E, Er D, Kaynak S. An Overview of Nd:YAG Laser Capsulotomy. Med Hypothesis Discov Innov Ophthalmol 20I4;3:45-50.

8. Ranta P, Tommila P, Kivela T. Retinal breaks and detachment after neodymium: YAG laser posterior capsulotomy: five-year incidence in a prospective cohort. J Cataract Refract Surg
2004;30:58-66. [CrossRef]

9. Altamirano D, Mermoud A, Pittet N, Van Melle G, Herbort CP. Aqueous humor analysis after $\mathrm{Nd}$ :Yag laser capsulotomy with the laser flare-cell meter. J Cataract Refract Surg 1992; 1:554-8.

10. Gore VS. The study of complications of Nd:YAG laser capsulotomy. Int J Bioinformative Res 2012:4:265-8. [CrossRef]

I I. Wielders LHP, Schouten JSAG, Winkens B, van den Biggelaar FJHM, Veldhuizen CA, Findl O, et al. European multicenter trial of the prevention of cystoid macular edema after cataract surgery in nondiabetics: ESCRS PREMED study report I. J Cataract Refract Surg 2018;44:429-39. [CrossRef]

12. Chun AG. Comparison of Incidence of Cystoid Macular Edema Following Nd: YAG Capsulotomy In Postoperative Treatment With Topical Steroids Versus Non-steroidal Anti-inflammatory Drugs. IOVS 2011;524516.

I3. Karahan E, Tuncer I, Zengin MO. The Effect of ND:YAG Laser Posterior Capsulotomy Size on Refraction, Intraocular Pressure Macular Thickness. J Ophthalmol 2014;2014:846385. [CrossRef]

14. Ari S, Cingü AK, Sahin A, Çinar Y, Çaça I. The effects of Nd:YAG laser posterior capsulotomy on macular thickness, intraocular pressure, and visual acuity. Ophthalmic Surg Lasers Imaging 20I 2;43:395-400. [CrossRef]

15. Jinagal J, Sahu S, Gupta G, Khurana S, Gupta R, Gupta PC, et al. Quantification of Inflammation Following Nd:YAG Laser Capsulotomy and Assessing the Anti-inflammatory Effects of Nepafenac 0.1\% and Betamethasone 0.I. Ocul Immunol Inflamm 2019:I-6. [CrossRef]

16. Meacock WR, Spalton DJ, Stanford MR. Role of cytokines in the pathogenesis of posterior capsule opacification. $\mathrm{Br} \mathrm{J} O \mathrm{Ph}-$ thalmol 2000:84;332-6. [CrossRef]

17. Murrill CA, Stanfield D, Van Brocklin MD. Capsulotomy. Optom Clin 1995:4;69-83.

18. Miyake K, Ota I, Miyake G, Numaga J. Nepafenac 0.1\% versus fluorometholone $0.1 \%$ for preventing cystoid macular edema after cataract surgery. J Cataract Refract Surg 201 I;37:158I-8.

19. Altiparmak UE, Ersoz I, Hazirolan D, Koklu B, Kasim R, Duman S. The impact of Nd:YAG capsulotomy on foveal thickness measurement by optical coherence tomography. Ophthalmic Surg Lasers Imaging 2010;41:67-7I. [CrossRef]

20. Giocanti-Aurégan A, Tilleul J, Rohart C, Touati-Lefloc'h M, Grenet T, Fajnkuchen F, et al. OCT measurement of the impact of $\mathrm{Nd}$ :YAG laser capsulotomy on foveal thickness. [Article in French] J Fr Ophtalmol 201 I;34:64I-6. [CrossRef]

2I. Wróblewska-Czajka E, Wylegała E, Tarnawska D, Nowińska A, Dobrowolski D. Assessment of retinal thickness obtain by optical coherence tomography after Nd: YAG capsulotomy. [Article in Polish] Klin Oczna 2012; I 14:194-7.

22. Türkoğlu B, Çelik E, Aksoy NÖ, Alagöz G. The Effects of Nd:YAG Laser Capsulotomy on Visual Acuity, Macular Thickness, and Intraocular Pressure in Diabetic Patients. Turkish J Ophthalmol 20I5;45:47-5I. [CrossRef] 
23. Mete M, Dogan M, Ercüment B, Kaya V, Yılmaz Ömer Faruk. Evaluation of Macular Thickness and Findings after Nd:YAG Laser Capsulotomy in Posterior Capsule Opacification. Istanbul Med J 2012;13:29-35. [CrossRef]

24. Yılmaz U, Küçük E, Ulusoy DM, Özköse A, Ataş M, Demircan $S$, et al. The assessment of changes in macular thickness in dia- betic and non-diabetic patients: the effect of topical ketorolac on macular thickness change after ND:YAG laser capsulotomy. Cutan Ocul Toxicol 2016;35:58-6I. [CrossRef]

25. Hoffman RS, Braga-Mele R, Donaldson K, Emerick G, Henderson $B$, Kahook M, et al. Cataract surgery and nonsteroidal antiinflammatory drugs. J Cataract Refract Surg 2016;42:1368-79. 